\title{
Plasma complement component 4 increases in patients with major depressive disorder
}

This article was published in the following Dove Press journal:

Neuropsychiatric Disease and Treatment

\author{
Jinxue Wei* \\ Ye Liu* \\ Liansheng Zhao \\ Xiao Yang \\ Peiyan Ni \\ Yingcheng Wang \\ Tao Li \\ Xiaohong $\mathrm{Ma}$
}

Psychiatric Laboratory and Mental Health Center, Huaxi Brain Research Center, West China Hospital of Sichuan University, Chengdu, China

*These authors contributed equally to this work
Correspondence: Xiaohong Ma Psychiatric Laboratory of West China Hospital, Sichuan University, I Keyuan Si Road, Chengdu, Sichuan, 61004I, China Email maxiaohong@scu.edu.cn

\begin{abstract}
Elevation of plasma inflammatory factors in major depressive disorder (MDD) has been repeatedly observed, but contradictory results have also been reported. Alteration of complement components in MDD may also contribute to the pathophysiology of MDD by participating in inflammation. The recent findings that complement component 4 (C4) was involved in neural synapse elimination and associated with schizophrenia implicated the potential roles of $\mathrm{C} 4$ in MDD. In this study, we analyzed the plasma concentration of complement $\mathrm{C} 4$ and inflammatory factors, including interleukin (IL)- $1 \beta$, IL-6, IL-8, IL-10, interferon- $\alpha$, interferon- $\gamma$ and tumor necrosis factor- $\alpha$, of 53 patients with MDD and 60 healthy individuals. The plasma of 17 patients out of 51 after antidepressant medication was also collected for analysis. The results showed that peripheral C4 in MDD was higher than that in healthy controls. No significant correlation of inflammatory factors or $\mathrm{C} 4$ with depressive or anxiety symptoms was found. Antidepressant medication significantly reduced plasma $\mathrm{C} 4$ of patients with MDD. Our results were consistent with previous findings that complement components were elevated in MDD and suggested that C4 might play a role in pathophysiology of MDD and could be a candidate in the research of biomarker and the pathophysiology of MDD.
\end{abstract}

Keywords: depression, C4, inflammation

\section{Introduction}

Major depressive disorder (MDD) is a common mental disorder characterized by depressed mood and/or loss of interest or pleasure that affects a person's personal, work, habits and general health. A recent global burden of disease study showed that MDD affects 253 million people (3.6\% of the global population) and was the second leading cause of years lived with disability in $2013 .{ }^{1}$

The etiology of MDD is not well understood. It has been widely accepted that the genetic, environmental and psychological factors contributed to the cause of MDD. ${ }^{2}$ In recent years, accumulating researches have focused on the roles of immune system in MDD. Multiple lines of evidence have shown the association between deregulation of immune system and MDD. ${ }^{3}$ The most robust evidence showing the association between immune system and MDD is from analysis of inflammatory factors in MDD. Higher levels of inflammatory factors, including interleukins (ILs), tumor necrosis factors (TNFs) and interferons (IFNs), in MDD than that found in healthy controls have been repeatedly reported. ${ }^{4-7}$ Moreover, exogenous administration of inflammatory factors induced depressive symptoms in both humans and rodents, ${ }^{8}$ implicating the important roles of inflammatory factors in MDD.

Besides inflammatory factors, complement system may also be involved in MDD. Complement system is a part of innate immune system and participates in the regulation 
of inflammation. ${ }^{9}$ A number of previous researches have indicated that complement components increased in MDD. ${ }^{10-12}$ In recent years, complement system was found to regulate synapse elimination in the central nervous system, ${ }^{13,14}$ suggesting that complement system may play multiple roles in MDD, either by participating in inflammation or by regulating neural functions. More recently, genetic variations of the complement component 4 (C4) were reported to account for the strongest genetic association with schizophrenia identified so far, ${ }^{15}$ which highlighted the importance of $\mathrm{C} 4$ in psychiatric diseases and implicated the potential roles of C4 in MDD.

The influence of antidepressant medication on inflammatory factors has also been reported. However, the results were inconsistent. ${ }^{16}$ Multiple factors, such as the types of antidepressant ${ }^{16}$ or the gender of patients, ${ }^{17}$ may contribute to the inconsistent results. Whether antidepressant medication has effects on peripheral C4 expression is unknown.

In this study, we collected peripheral blood of the patients with depression and healthy controls and analyzed concentration of $\mathrm{C} 4$ and multiple inflammatory factors in plasma. Effects of antidepressant medication on the peripheral C4 and inflammatory factors were also evaluated.

\section{Subjects and methods Study participants}

Han Chinese patients with depression aged 18 through 60 years were recruited in the Mental Health Center of West China Hospital, Sichuan University. The inclusion criteria of this study were as follows: 1) meeting the criteria for MDD as specified in the Diagnostic and Statistical Manual of Mental Disorders, Fourth Edition (DSM-IV); 2) 17-item Hamilton depression rating scale (HAMD) (HAMD-17) scores being $>17 ; 3$ ) antidepressants or antipsychotics-naïve, or antidepressants or antipsychotics-free for at least 3 months; and 4) Wechsler's intelligence test scores being $\geq 90$. The exclusion criteria were as follows: 1) having neurogenic diseases, endocrine diseases and metabolic disorders or serious physical diseases; 2) having other psychiatric disorders, such as dementia, schizophrenia, bipolar disorder and substance abuse; 3 ) having obvious psychosocial factors, such as job failure, marriage failure, lovelorn, traffic accident and economic problems; 4) receiving hormone medication or 5) being pregnant or breastfeeding. All the patients were evaluated with HAMD-17 and 24-item Hamilton anxiety rating scale (HAMA-24).

Patients with MDD were started on antidepressant treatment on the day they were enrolled in this study and were invited for a follow-up survey 6 weeks after antidepressant medication.

Healthy volunteers were also recruited if they 1) were Han Chinese aged 18 through 60 years; 2) had Wechsler's intelligence test scores being $\geq 90$ and 3 ) had normal performance at work. The individuals who had DSM-IV axis I and II disorders, organic brain diseases or a family history of mental disorders were excluded from this study.

The study was approved by the Institutional Ethics Committee of Sichuan University, and all participants provided written informed consent. All study procedures were in accordance with the Declaration of Helsinki.

\section{Preparation of plasma}

Peripheral blood of patients and healthy controls was collected in tubes anticoagulated using EDTA on the day when they were enrolled in this study. Peripheral blood of the patients with follow-up was collected on the day of follow-up. The blood samples were then centrifuged at $2,000 \times g$ for 5 minutes, and upper plasma was transferred to a fresh tube and stored at $-80^{\circ} \mathrm{C}$.

\section{Analysis of immune-related factors in plasma}

Concentration of immune-related factors in plasma was measured by a multiplexed flow cytometric assay using a Milliplex kit (HNDG2MAG-36K; Millipore, Billerica, MA, USA) for $\mathrm{C} 4$ and a Milliplex kit (HCYTOMAG-60K; Millipore) for IL-1 $\beta$, IL-6, IL-8, IL-10, TNF- $\alpha$, IFN- $\alpha$ and IFN- $\gamma$. The assays were performed by Bio-atom Biotechnology (Chengdu, China) according to the instruction of the kits.

\section{Statistical analysis}

Statistical analysis was performed using the SPSS 18.0 software package (SPSS, Chicago, IL, USA). The independent samples $t$-test was used to compare age between healthy controls and the patients with depression. Chi-square test was used to compare gender difference between the patients and healthy controls. The concentrations of immune-related factors in healthy population and the patients with depression were compared using the Mann-Whitney (nonparametric) test. The Wilcoxon paired test was performed to compare the concentrations of immune-related factors of the patients with depression before or after antidepressant medication. The Spearman correlation was used to evaluate the relationship between the concentrations of immune-related factors and HAMD or HAMA scores in the patients with depression. All the $p$-values $<0.05$ were considered significant. 
Table I Demographic characteristics of all study participants

\begin{tabular}{|c|c|c|c|c|c|c|c|}
\hline & \multirow{2}{*}{$\begin{array}{l}\text { Health } \\
(n=60)\end{array}$} & \multicolumn{3}{|c|}{ All patients $(n=53)$} & \multicolumn{3}{|c|}{ Patients with follow-up $(n=17)$} \\
\hline & & & $\chi^{2}$ or $\mathbf{t}$ & $p$-value & & $\chi^{2}$ or $\mathrm{t}$ & $p$-value \\
\hline Age (years) & $29.70 \pm 9.99$ & $30.13 \pm 10.76$ & 0.23 & 0.83 & $27.4 I \pm 9.40$ & -0.73 & 0.48 \\
\hline Gender (M/F) & $22 / 38$ & $22 / 31$ & 0.28 & 0.59 & $9 / 8$ & 1.46 & 0.23 \\
\hline Education (years) & $13.54 \pm 2.87$ & $12.58 \pm 3.60$ & -1.55 & 0.12 & $13.43 \pm 2.99$ & -1.67 & 0.11 \\
\hline Height $(\mathrm{cm})$ & $163.43 \pm 8.53$ & $164.5 \pm 8.46$ & 0.67 & 0.51 & $168.13 \pm 8.62$ & 1.94 & 0.07 \\
\hline Weight (kg) & $57.98 \pm 10.48$ & $56.86 \pm 11.52$ & -0.53 & 0.60 & $60.56 \pm 13.91$ & 0.67 & 0.50 \\
\hline
\end{tabular}

Note: Data presented as mean \pm standard deviation unless otherwise stated.

\section{Results}

\section{Demographic and clinical characteristics of the participants}

Fifty-three patients with depression ( 22 males and 31 females) and 60 healthy individuals ( 22 males and 38 females) were included in this study. The average age of the patients with depression and healthy controls was $30.13 \pm 10.76$ and $29.70 \pm 9.99$ years, respectively. There was no statistically significant difference of age $(\mathrm{t}=0.23, p=0.83)$ and gender $\left(\chi^{2}=0.28, p=0.59\right)$ between the patients and healthy controls. The average of education years $(\mathrm{t}=-1.55, p=0.12)$, height $(\mathrm{t}=0.67, p=0.51)$ and weight $(\mathrm{t}=-0.53, p=0.60)$ in the patients did not significantly differ from that in the healthy controls (Table 1). The average HAMD and HAMA scores of all the patients with depression were $22.6 \pm 3.59$ and $13.8 \pm 6.29$, respectively (Table 2).

Of the 53 patients, 17 ( 9 males and 8 females) participated in a follow-up survey 6 weeks after antidepressant medication. The average age of the patients at follow-up was $27.41 \pm 9.40$ years and did not differ from that of the healthy controls ( $\mathrm{t}=-0.73, p=0.40)$. There was no statistically significant difference of the gender $\left(\chi^{2}=1.46, p=0.23\right)$ between the patients at follow-up and the healthy controls. The average HAMD and HAMA scores of the patients at follow-up were $21.76 \pm 2.77$ and $14.06 \pm 6.19$ before antidepressant medication and $6.52 \pm 3.76$ and $6.58 \pm 4.02$ after antidepressant medication, respectively. Antidepressants used in this study included venlafaxine $(n=8)$, sertraline $(n=3)$, paroxetine $(n=3)$, citalopram $(n=2)$ and mirtazapine $(n=1)$.

Table 2 HAMD and HAMA of patients with depression

\begin{tabular}{lllll}
\hline & $\begin{array}{l}\text { All patients } \\
(\mathbf{n}=53)\end{array}$ & \multicolumn{3}{l}{ Patients with follow-up $(\mathbf{n}=\mathbf{1 7})$} \\
\cline { 3 - 5 } & & $\begin{array}{l}\text { Before } \\
\text { medication }\end{array}$ & $\begin{array}{l}\text { After } \\
\text { medication }\end{array}$ & $\begin{array}{l}\text { Reduction } \\
\text { rate, \% }\end{array}$ \\
\hline HAMD & $22.6 \pm 3.59$ & $21.76 \pm 2.77$ & $6.52 \pm 3.76$ & $70.5 \pm 13.2$ \\
HAMA & $13.8 \pm 6.29$ & $14.06 \pm 6.19$ & $6.58 \pm 4.02$ & $49.6 \pm 32.7$
\end{tabular}

Note: Data presented as mean \pm standard deviation.

Abbreviations: HAMA, Hamilton anxiety rating scale; HAMD, Hamilton depression rating scale.

\section{Analysis of concentration of immune- related factors in plasma in the patients with MDD and healthy controls}

The concentration of $\mathrm{C} 4$ was significantly higher $(p<0.0001)$ in the patients with depression than that in the healthy controls (Table 3). There were no significant differences of the concentrations of IL-1 $\beta$, IL-6, IL-8, IL-10, IFN- $\alpha$, IFN- $\gamma$ and TNF- $\alpha$ between the patients with depression and healthy controls (Table 3). We did not find a significant correlation of HAMD or HAMA scores with the concentration of $\mathrm{C} 4$ or inflammatory factors (Table 4).

\section{Evaluation of the effects of antidepressant medication on C4 and inflammatory factors}

The concentration of $\mathrm{C} 4$ in plasma of the patients after antidepressant medication was significantly lower than that before antidepressant medication $(\mathrm{Z}=-3.20, p=0.001)$. The antidepressant medication did not significantly alter the concentrations of IL-1 $\beta$, IL-6, IL-8, IL-10, IFN- $\alpha$, IFN- $\gamma$ and TNF- $\alpha$ in plasma (Table 5).

The concentration of $\mathrm{C} 4$ in plasma of the patients after antidepressant medication did not differ from that of the healthy controls $(\mathrm{Z}=-0.18, p=0.85$; Table 6 ).

Table 3 Comparison of plasma concentrations of inflammatory factors and $\mathrm{C} 4$ between healthy controls and patients with MDD

\begin{tabular}{lllll}
\hline & Median & & $\mathbf{Z}$ & $p$-value \\
\cline { 2 - 3 } & Health & MDD & & \\
\hline IL-I $\beta$ & 0.8 & 0.95 & $-0.8 \mathrm{I}$ & $0.4 \mathrm{I}$ \\
IL-6 & 1.59 & $\mathrm{I} .79$ & -2.06 & 0.14 \\
IL-8 & 0.82 & 1.09 & -0.56 & 0.58 \\
IL-I0 & 6.12 & 7.15 & -1.17 & 0.24 \\
IFN- $\alpha$ & 10.01 & 12.94 & -0.80 & 0.43 \\
IFN- $\gamma$ & 5.20 & 5.20 & -0.72 & 0.47 \\
TNF- $\alpha$ & 3.53 & 3.44 & -0.86 & 0.39 \\
C4 & 58.3 & 84.85 & -5.04 & $<0.000$ I \\
\hline
\end{tabular}

Abbreviations: IFN, interferon; IL, interleukin; MDD, major depressive disorder; TNF, tumor necrosis factor. 
Table 4 The analysis of correlation between inflammatory factors or C4 and HAMD/HAMA scores in patients with depression

\begin{tabular}{llllll}
\hline & \multicolumn{2}{l}{ HAMD } & & \multicolumn{2}{l}{ HAMA } \\
\cline { 2 - 3 } \cline { 5 - 6 } & $\mathbf{r}$ & $\boldsymbol{p}$-value & & $\boldsymbol{r}$ & $\boldsymbol{p}$-value \\
\hline IL-I $\beta$ & 0.09 & 0.5 I & & 0.23 & 0.10 \\
IL-6 & -0.14 & 0.31 & 0.11 & 0.42 \\
IL-8 & 0.03 & 0.82 & 0.12 & 0.39 \\
IL-I0 & -0.03 & 0.82 & 0.08 & 0.57 \\
IFN- $\alpha$ & -0.02 & 0.88 & -0.01 & 0.94 \\
IFN- $\gamma$ & 0.02 & 0.91 & 0.10 & 0.46 \\
TNF- $\alpha$ & -0.29 & 0.04 & 0.02 & 0.89 \\
C4 & 0.09 & 0.5 I & 0.08 & 0.56 \\
\hline
\end{tabular}

Abbreviations: HAMA, Hamilton anxiety rating scale; HAMD, Hamilton depression rating scale.

\section{Discussion}

In this study, we found that peripheral C4 in MDD was higher than that in the healthy controls (Table 3). C4 is essential for the activation of complement cascade that is involved in the development of inflammation. ${ }^{18}$ Therefore, the higher concentration of $\mathrm{C} 4$ in MDD than that in the healthy controls may be a reflection of the inflammation in MDD. $\mathrm{C} 4$ is also expressed by neurons and plays a role in synapse elimination. ${ }^{13,15}$ Whether $\mathrm{C} 4$ is involved in MDD by directly regulating function of neurons in brain is unknown. Analysis of the association of peripheral $\mathrm{C} 4$ expression with $\mathrm{C} 4$ in the central nervous system in MDD in the future would be helpful for understanding the role of 44 in MDD.

After antidepressant medication, the concentration of plasma $\mathrm{C} 4$ in the patients with depression was reduced (Table 5) and did not show any significant difference when compared with healthy controls in this study (Table 6). The mechanism of suppression of $\mathrm{C} 4$ by antidepressant medication would be an interesting topic in any future study. Antidepressants have long been known to have the ability to reduce inflammatory factors in the patients with MDD

Table 5 Effects of antidepressant medication on plasma concentration of inflammatory factors and C4

\begin{tabular}{lllll}
\hline & Median & & $Z$ & P-value \\
\cline { 2 - 3 } & Before & After & & \\
\hline IL-I $\beta$ & 1.35 & 1.29 & -1.37 & 0.17 \\
IL-6 & 1.29 & 0.92 & -0.64 & 0.52 \\
IL-8 & 3.76 & 2.79 & -0.16 & 0.88 \\
IL-I0 & 0.78 & 0.6 & -0.85 & 0.39 \\
IFN- $\alpha$ & 3.62 & 3.2 & -1.16 & 0.24 \\
IFN- $\gamma$ & 12.94 & 16.83 & -0.88 & 0.38 \\
TNF- $\alpha$ & 7.15 & 6.47 & -1.59 & 0.11 \\
C4 & 125.38 & 50.22 & -3.20 & $\mathbf{0 . 0 0 I}$ \\
\hline
\end{tabular}

Table 6 Comparison of plasma C4 between healthy controls and patients after antidepressant medication

\begin{tabular}{lllll}
\hline & Median & Z & p-value \\
\cline { 2 - 3 } & Health $(\mathbf{n}=\mathbf{6 0})$ & MDD $(\mathbf{n}=17)$ & & \\
\hline $\mathrm{C} 4(\mu \mathrm{g} / \mathrm{mL})$ & $58.3 \pm 47.8$ & $50.2 \pm 38.0$ & -0.18 & 0.85 \\
\hline
\end{tabular}

Note: Data presented as mean \pm standard deviation unless otherwise stated. Abbreviation: MDD, major depressive disorder.

or animal models. ${ }^{19}$ Because plasma $\mathrm{C} 4$ may be affected by inflammation, ${ }^{9}$ the mechanism of the anti-inflammation activity of antidepressants may be enrolled in the suppression of $\mathrm{C} 4$. Previous studies have suggested that regulation of hypothalamic-pituitary-adrenal axis activity ${ }^{20}$ or inhibition of immune cell activation ${ }^{21,22}$ might contribute to the effects of antidepressants on inflammation, which could be involved in any future study of the mechanism of suppression of $\mathrm{C} 4$ by antidepressants.

Although quite a number of researches reported an increase of peripheral inflammatory factors in MDD, contradictory results were also observed. ${ }^{4,6}$ In this research, we did not find any significant difference of the concentrations of IL-1 $\beta$, IL-6, IL-8, IL-10, IFN- $\alpha$, IFN- $\gamma$ and TNF- $\alpha$ in MDD compared with healthy controls, which may partially be due to the large variation of their concentration in plasma (Table 3). The peripheral inflammatory factors are sensitive to stimulation such as injury, infection ${ }^{23}$ and stress, ${ }^{24}$ which would result in large variation of concentration in plasma. By comparison, the variation of plasma $\mathrm{C} 4$ concentration is relatively small. Furthermore, the source of plasma $\mathrm{C} 4$ is different from that of inflammatory factors. Plasma $\mathrm{C} 4$ is mainly produced by hepatocytes, while most plasma inflammatory factors are produced locally, ${ }^{25}$ which may contribute to the different results between $\mathrm{C} 4$ and inflammatory factors in this study. Taken together, our results suggested that further research on C4 in MDD would be helpful for identifying the biomarker of MDD.

There were some limitations in this research. First, the sample size was relatively small. Second, 5 antidepressants were used. Third, we failed to recruit patients with moderate response to antidepressant medication, probably due to the weak intention of the patients with moderate response to participate in the follow-up interviews. Therefore, no conclusion can yet be drawn on whether the effects of antidepressant medication on inflammatory factors are dependent on the kinds of antidepressants or the response of the patients with MDD.

In summary, we found that plasma $\mathrm{C} 4$ was elevated in MDD compared with healthy controls and antidepressant medication decreased plasma C4 in MDD. Our results 
suggested that $\mathrm{C} 4$ might be a candidate in the research of biomarker and pathophysiology of MDD.

\section{Acknowledgments}

This research was partly supported by the National High Technology Research and Development Program of China (863 Program, 2015AA020513), the National Science and Technology Program (2015BAI13B02) and the National Natural Science Foundation of China (81671344, 91332205).

\section{Disclosure}

All authors report no conflicts of interest in this work.

\section{References}

1. Global Burden of Disease Study C. Global, regional, and national incidence, prevalence, and years lived with disability for 301 acute and chronic diseases and injuries in 188 countries, 1990-2013: a systematic analysis for the Global Burden of Disease Study 2013. Lancet. 2015;386(9995):743-800.

2. Ebmeier KP, Donaghey C, Steele JD. Recent developments and current controversies in depression. Lancet. 2006;367(9505):153-167.

3. Kohler O, Krogh J, Mors O, Benros ME. Inflammation in depression and the potential for anti-inflammatory treatment. Curr Neuropharmacol. 2016;14(7):732-742.

4. Haapakoski R, Mathieu J, Ebmeier KP, Alenius H, Kivimaki M. Cumulative meta-analysis of interleukins 6 and 1 beta, tumour necrosis factor alpha and $\mathrm{C}$-reactive protein in patients with major depressive disorder. Brain Behav Immun. 2015;49:206-215.

5. Miller AH, Raison CL. The role of inflammation in depression: from evolutionary imperative to modern treatment target. Nat Rev Immunol. 2016;16(1):22-34

6. Hiles SA, Baker AL, de Malmanche T, Attia J. Interleukin-6, C-reactive protein and interleukin-10 after antidepressant treatment in people with depression: a meta-analysis. Psychol Med. 2012;42(10):2015-2026.

7. Dowlati Y, Herrmann N, Swardfager W, et al. A meta-analysis of cytokines in major depression. Biol Psychiatry. 2010;67(5):446-457.

8. Lotrich FE. Inflammatory cytokine-associated depression. Brain Res. 2015;1617:113-125.

9. Oikonomopoulou K, Ricklin D, Ward PA, Lambris JD. Interactions between coagulation and complement - their role in inflammation. Semin Immunopathol. 2012;34(1):151-165.

10. Stelzhammer V, Haenisch F, Chan MK, et al. Proteomic changes in serum of first onset, antidepressant drug-naive major depression patients. Int J Neuropsychopharmacol. 2014;17(10):1599-1608.
11. Boyle SH, Jackson WG, Suarez EC. Hostility, anger, and depression predict increases in C3 over a 10-year period. Brain Behav Immunity. 2007;21(6):816-823.

12. Maes M, Delange J, Ranjan R, et al. Acute phase proteins in schizophrenia, mania and major depression: modulation by psychotropic drugs. Psychiatry Res. 1997;66(1):1-11.

13. Stevens B, Allen NJ, Vazquez LE, et al. The classical complement cascade mediates CNS synapse elimination. Cell. 2007;131(6):1164-1178.

14. Bialas AR, Stevens B. TGF-beta signaling regulates neuronal C1q expression and developmental synaptic refinement. Nat Neurosci. 2013;16(12):1773-1782.

15. Sekar A, Bialas AR, de Rivera H, et al. Schizophrenia risk from complex variation of complement component 4. Nature. 2016;530(7589): $177-183$.

16. Hannestad J, DellaGioia N, Bloch M. The effect of antidepressant medication treatment on serum levels of inflammatory cytokines: a meta-analysis. Neuropsychopharmacology. 2011;36(12):2452-2459.

17. Vogelzangs N, Duivis HE, Beekman AT, et al. Association of depressive disorders, depression characteristics and antidepressant medication with inflammation. Transl Psychiatry. 2012;2:e79.

18. Morgan BP, Harris CL. Complement, a target for therapy in inflammatory and degenerative diseases. Nat Rev Drug Discov. 2015;14(12): $857-877$.

19. Kenis G, Maes M. Effects of antidepressants on the production of cytokines. Int J Neuropsychopharmacol. 2002;5(4):401-412.

20. Leonard BE. Impact of inflammation on neurotransmitter changes in major depression: an insight into the action of antidepressants. Prog Neuropsychopharmacol Biol Psychiatry. 2014;48:261-267.

21. Xia Z, DePierre JW, Nassberger L. Tricyclic antidepressants inhibit IL-6, IL-1 beta and TNF-alpha release in human blood monocytes and IL-2 and interferon-gamma in T cells. Immunopharmacology. 1996;34(1):27-37.

22. Hwang J, Zheng LT, Ock J, et al. Inhibition of glial inflammatory activation and neurotoxicity by tricyclic antidepressants. Neuropharmacology. 2008;55(5):826-834.

23. Tisoncik JR, Korth MJ, Simmons CP, Farrar J, Martin TR, Katze MG. Into the eye of the cytokine storm. Microbiol Mol Biol Rev. 2012; 76(1):16-32.

24. Berk M, Williams LJ, Jacka FN, et al. So depression is an inflammatory disease, but where does the inflammation come from? BMC Med. 2013;11:200.

25. Lubbers R, van Essen MF, van Kooten C, Trouw LA. Production of complement components by cells of the immune system. Clin Exp Immunol. 2017;188(2):183-194.
Neuropsychiatric Disease and Treatment

\section{Publish your work in this journal}

Neuropsychiatric Disease and Treatment is an international, peerreviewed journal of clinical therapeutics and pharmacology focusing on concise rapid reporting of clinical or pre-clinical studies on a range of neuropsychiatric and neurological disorders. This journal is indexed on PubMed Central, the 'PsycINFO' database and CAS,

\section{Dovepress}

and is the official journal of The International Neuropsychiatric Association (INA). The manuscript management system is completely online and includes a very quick and fair peer-review system, which is all easy to use. Visit http://www.dovepress.com/testimonials.php to read real quotes from published authors. 